\section{Loyalitas Kreativitas \\ Aldi Masyarakat Kreatif}

P-ISSN 2722-2101, E-ISSN 2722-4201

Program Studi Ekonomi Manajemen Universitas Pamulang

Jurnal LOKABMAS Kreatif Vol. 01, No. 01, Hal. 71- 75

Email:jurnalkreatif.manajemen@gmail.com

\title{
PROGAM PENDAMPINGAN DAN PENYELENGGARAAN PENDIDIKAN ANAK PADA USIA DINI TERHADAP PRESTASI BELAJAR DILINGKUNGAN RT O20 RW 009 .KEL GIRI PENI.KEC WATES. YOGYAKARTA.
}

\author{
Veta Lidya Delimah Pasaribu, Bulan Oktrima, Budhi Prabowo, Nurmin Arianto, Ugeng Budi \\ Haryoko
}

Dosen Ekonomi Fakultas Ekonomi Universitas Pamulang

\begin{abstract}
Email dosen01889@unpam.ac.id, dosen00790@unpam.ac.id, dosen02034@unpam.ac.id, dosen01118@unpam.ac.id, dosen00962@unpam.ac.id
\end{abstract}

\begin{abstract}
ABSTRAK
Tujuan dari Kegiatan Pengabdian Kepada Masyarakat adalah untuk melaksanakan salah satu Tri Darma Perguruan Tinggi.Selain itu diharapkan dengan pengabdian kepada masyarakat tersebut keberadaan perguruan tinggi dapat memberikan kontribusi besar kepada pengembangan dan penerapan keilmuan kepada masyarakat.

Metode yang digunakan pada Pengabdian Kepada Masyarakat ini berupa ekspositori yaitu penyampaian materi secara verbal dan inquiry yaitu pembelajaran yang menekankan pada proses berpikir kritis dan analitis terkait kelimuan manajemen sumber daya manusia dan manajemen pemasaran dengan pemahaman mendalam terkait materi bagaimana menentukan masa depan .

Hasil pengabdian masyarakat yang diperoleh adalah bertambahnya keilmuan bagi para orang tua dan anak- anak dilingkungan Rt 20 Rw 9 kel.giri peni,Kec wates. yogyakarta, agar mereka memiliki pandangan yang baik focus sasaran dan program kerja pembangunan pendidikan harus mampu menjawab tuntutan mutu dari kapasitas pendidikan yang semakin besar dengantetap berupaya mendorong akses pendidikan yang semakin meluas, mudah, danakuntabel. Memasuki tahun 2019, seiring catatan pencapaian pelaksanaan program tahun 2018 dan adanya kebijakan reformasi birokrasi (restrukturisasi) di lingkungan Kementerian Pendidikan dan Kebudayaan, Direktorat Jenderal Pendidiikan Anak Usia Dini, Nonformal dan Informal (PAUDNI) telah menyusun kebijakan dan program tahun 2012 sesuai dengan tuntunan beban garapan yang semakin besar dengan tetap memperhatikan keberlanjutan dan peningkatan kualitas pencapaian program anggaran 2019 seyogyanya dapat dipahami oleh seluruh pemangku kepentingan dan dapat dilaksanakan sesuai dengan tujuan, target, dan sasaran Ilmu yang diperoleh pada Pengabdian Masyarakat kali ini diharapkan mampu memberikan semangat baru bagi kita dalam menyampaikan materi dan motivasi serta berkontribusi bagi generasi muda, baik dilingkungan sekolah, kampus dan keluarga.
\end{abstract}

\section{Kata Kunci: Pendidikan Anak, Pretasi Belajar, PAUD, Usia Dini}

\section{ABSTRAC}

The purpose of Community Service Activities is to carry out one of the Tri Darma of Higher Education. In addition, community service is expected to provide a major contribution to the development and application of knowledge to the community.

The method used in this Community Service is expository, namely the delivery of material verbally and inquiry, namely learning that emphasizes the critical and analytical thinking processes related to human resource management and marketing management with a deep understanding of material related to how to determine the future.

The results of community service obtained are increased knowledge for parents and children in the neighborhood of Rt $20 \mathrm{Rw} 9$ kel .iri peni, Kec wates. yogyakarta, so that they have a good view the 


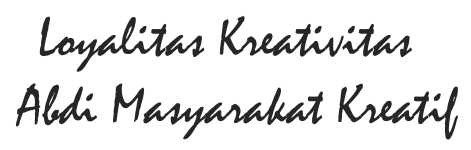

P-ISSN 2722-2101, E-ISSN 2722-4201

Program Studi Ekonomi Manajemen Universitas Pamulang Jurnal LOKABMAS Kreatif Vol. 01, No. 01, Hal. 71- 75

Email:jurnalkreatif.manajemen@gmail.com

focus of the target and the work program of education development must be able to answer the quality demands of an increasingly educational capacity by striving to encourage access to education that is increasingly widespread, easy, and accountable. Entering 2019, in line with the achievement of 2018 program implementation and the existence of a policy of bureaucratic reform (restructuring) within the Ministry of Education and Culture, the Directorate General of Early Childhood, Non-Formal and Informal Education (PAUDNI) has compiled 2012 policies and programs in accordance with the guidance of the greater burden of cultivation while still paying attention to sustainability and improving quality achievement of the program within the framework of the vision, mission and overall national education development strategy. The direction of policies and programs for early childhood education, non-formal and informal education for the 2019 budget year should be understood by all stakeholders and can be carried out in accordance with the goals, targets, and targets of the Science obtained at Community Service this time is expected to be able to provide a new spirit for us in deliver material and motivation and contribute to the younger generation, both within the school, campus and family.

\section{Keywords:Children'sEducation,LearningPretexts,PAUD,EarlyAge}

\section{PENDAHULUAN}

Kebijakan pembangunanpendidikan nasional $\mathrm{t}$ ahun 2014-2018 menekankanpada penguatan layanan pendidikan yang relevan, berkualitas dan berdaya saingdalam rangka mempersiapkan insan Indonesia yang cerdas komprehensif. Memasukitahun ketiga pelaksanaan rencana strategis pembangunan pendidikan tersebut danseiring dengan penataan organisasi di lingkungan Kementerian Pendidikan danKebudayaan, Direktorat Jenderal Pendidikan Anak Usia Dini, Nonformal dan Informal (PAUDNI) sesuai dengan tugas dan fungsinya telah mengembangkan danmelaksanakan kebijakan dan program pembangunan pendidikan anak usia dini,pendidikan nonformal dan informal,mencakup penyediaanlayanan pendidikan anak usia dini, layanan kursus dan pelatihan, layanan pendidikan masyarakat, danpenyediaan dan peningkatan mutu pendidik dan tenaga kependidikan PAUDNI.Dihadapkan pada tantangan layanan. Program Pendidikan anak usia

dini, pendidikan nonformal dan informal pada tahun 2019 diharapkan dapatmemberikan kesempatan yang lebih luas, terbuka, merata dan bermutu bagi seluruhlapisan masyarakat untuk belajar dan memberdayakan diri melalui layananpendidikan anak usia dini, layanan pendidikan masyarakat, layanan kursus danpelatihan yang didukung dengan penyediaan dan peningkatan mutu pendidik dantenaga kependidikan PAUDNI.Kebijakan dan program PAUDNI pada tahun 2019 selain merupakan upaya untuk mencapai target prioritas pembangunan sebagaimana yang telah ditetapkan secaranasional dalam RPJM dan Rencana Strategis Kementerian Pendidikan danKebudayaan Tahun 2014-2018, tetapi juga sekaligus merupakan upaya pelaksanaan Peraturan Menteri Pendidikan Nasional Nomor 36 tahun 2010 tentang Organisasidan Tata Kerja di lingkungan Kementerian Pendidikan Nasional20.

Komitmen global dalam mencapai target pembangunan dunia dimana Indonesia telahikut menyepakati.Indonesia berperan serta dalam penandatanganan perjanjian internasional diantaranya Millenium Development Goal (MDG's) tahun 2000,Deklarasi Dakar tahun 2000 tentang Education for All / Pendidikan Untuk Semua (PUS), Convention on Elimination of Discrimination Against Women (CEDAW) tahun 1989, konvensi HakHak Anak tahun 1989. Semua kesepakatan global di atas pada intinya adalah meminta tanggung jawab negara-negara untuk memenuhi hak-hak warga negara secara universal tanpa diskriminasi di bidang pendidikan. Berbagai kebijakan dan program PAUDNI disusun untuk memberikan pelayanan pendidikan yang terbaik bagi masyarakat.Keberhasilan penyelenggaraan program PAUDNI sangat terkait dengan partisipasi pemerintah provinsi dan pemerintah kabupaten/kota serta partisipasi aktif dari 


\section{Loyalitas Kreativitas \\ Aldi Masyarakat Kreatif}

P-ISSN 2722-2101, E-ISSN 2722-4201

Program Studi Ekonomi Manajemen Universitas Pamulang Jurnal LOKABMAS Kreatif Vol. 01, No. 01, Hal. 71- 75

Email:jurnalkreatif.manajemen@gmail.com seluruh pemangku kepentingan di sektor pendidikan, dan keseluruhan. Sinergi antara pemerintah baik pusat maupun daerah dengan seluruh pemangku kepentingan seperti satuansatuanpendidikan, organisasi pendidik dan tenaga kependidikan, organisasi penyelenggara pendidikan, lembaga swadaya masyarakat, organisasi sosial dan keagamaan, hingga lembaga-lembaga keilmuan dan perguruan tinggi, sangat menentukan keberhasilan pelaksanaan program yang telah disusun karena merupakan garda terdepan dalam pelaksanaan program di lapangan.Untuk menjamin pelaksanaan program dapat berjalan dengan baik diperlukan pemahaman yang memadai dari seluruh pemangku kepentingan tersebut mengenaiarah kebijakan dan program yang telah ditetapkan pada tahun 2019 ini. Untuk itumaka perlu diterbitkan Pedoman Penyelenggaraan Program Pendidikan Anak Usia Dini, Nonformal, dan Informal yang diharapkan dapat menjadi acuan dan petunjuk umum yang menguraikan berbagai aktivitas perencanaan, pelaksanaan dan pengendalian mutu program di lingkungan Direktorat Jenderal PAUDNI pada satuan kerja di pusat (Setditjen, Direktorat, PPPNFI, BP-PNFI), dan daerah (provinsi dan kabupaten/kota) sehingga dapat dilaksanakan secara efektif dan efisien serta memenuhi prinsip-prinsip tata kelola kepemerintahan yang baik, transparan, dan akun tabel.Disamping itu, dalam rangka memenuhi program yang benarbenar bermutu danrelevan dengan perkembangan kemajuan masyarakat dan kebutuhan belajar masyarakat, maka pengkajian dan pengembangan model pendidikan anak usia dini, pendidikan nonformal dan informal, serta berbagai program percontohan akan lebih ditingkatkan secara berkelanjutan yang dilaksanakan oleh UPT Pusat berkoordinasi dengan UPT Daerah. Program-program itu pun harus difahami dengan baik oleh seluruh stake holder sehingga untuk selanjutnya rujukan pelaksanaanya diatur dalam pedoman tersendiri melengkapi pedomanpedoman teknis lainnya yang akan diterbitkan kemudian. Dengan adanya materi ini tentang bagaimana mempertimbangakan anak dari usia dini, Para pemikiran orang tua menjadi terbuka dan mampu mengatur arah hidup mereka secara mandiri dan bermanfaat untuk orang lain. Oleh karena itu ,Perlu adanya dukungan dan pihak Yayasan untuk menjalankan pelatihan ini agar tersampaikan dengan maksimal

\section{RUMUSAN MASALAH}

Dengan mempertimbangkan latar belakang yang telah diutarakan diatas kami berinisiatif untuk membentu pengabdian masyarakat bagi orang tua dan anak- anak di lingkungan rt 20 rw 09 kel giri peni, kec.wates, Yogyakarta siswa melalui progam penyuluhan materi progam pendampingan dan penyelengaraan pendidikan anak usia dini terhadap prestasi belajar

Membekali anak-anak para orang tua dan anak- anak dengan penyuluhan materi progam pendampingan dan penyelengaraan pendidikan anak usia dini terhadap prestasi belajar

\section{TUJUAN PELAKSANAAN}

1. Membantu memberikan arahan terhadap orang tua dilingkungan rt 20 rw 09 kel.giri peni, kel wates, Yogyakarta

2. Membuka paradigma orang tua dan anakdilingkungan rt 20 rw 09 kel.giri peni, kel wates,yogyakarta

3. Memberikan semangat dan motivasi bagi orang tua dan anak- dilingkungan rt 20 rw 09 kel.giri peni, kel wates,yogyakarta dalam menjalani kehidupan

\section{TINJAUAN PUSTAKA}

Menurut Sicilia Sawitri, dkk (2010:406) industri garmen merupakan industri yang mengolah sebuah produk yang berasal dari penggabungan dan penjahitan berbagai potongan dan komponen hingga menjadi suatu bentuk jadi berupa busana. Sedangkan kain perca merupakan limbah garmen yang berupa sisa potongan pada proses pengguntingan kain, baik pada pembuatan pakaian yang dilakukan oleh ibu rumah tangga, industri kecil, maupun industri besar.

\section{D a s a r H u k u m}




\section{Loyalitas Kreativitas \\ Aldi Masyarakat Kreatif}

P-ISSN 2722-2101, E-ISSN 2722-4201

Program Studi Ekonomi Manajemen Universitas Pamulang Jurnal LOKABMAS Kreatif Vol. 01, No. 01, Hal. 71- 75

Email:jurnalkreatif.manajemen@gmail.com
1. Undang-Undang Nomor 17 Tahun 2003 tentang Keuangan Negara

2. Undang-Undang Nomor 20 tahun 2003 tentang Sistem Pendidikan Nasional

3. Undang-Undang Nomor 1 tahun 2004 tentang Perbendaharaan Negara

4. Undang-undang Nomor 25 Tahun 2004 tentang Sistem PerencanaanPembangunan Nasional;

5. Undang-Undang Nomor 32 tahun 2004 tentang Pemerintah Daerah

6. Undang-undang Nomor 43 tahun 2007 tentang Perpustakaan

7. Undang-undang Nomor 17 tahun 2007 tentang Rencana Pembangunan JangkaPanjang Nasional (RPJPN) 2005-2025;8.

8. Peraturan Pemerintah Republik Indonesia Nomor 20 Tahun 2004 tentangRencana Kerja Pemerintah

9. Peraturan Pemerintah Republik Indonesia Nomor 21 Tahun 2004 tentangPenyusunan Rencana Kerja dan Anggaran Kementerian Negara/Lembaga

10. Peraturan Pemerintah No. 19 tahun 2005 tentang Standar Nasional Pendidikan(SNP)

11. Peraturan Pemerintah nomor 17 tahun 2010 tentang Pengelolaan danPenyelenggaraan Pendidikan

12. Peraturan Presiden Republik Indonesia Nomor 67 Tahun 2010 tentangKedudukan, Tugas Pokok, Fungsi, Susunan Organisasi dan Tata KerjaKementerian Negara Republik Indonesia

13. Peraturan Presiden Republik Indonesia Nomor 5 tahun 2010 tentang RencanaPembangunan Jangka Menengah Nasional (RPJMN) Tahun 2010-2014

14. Instruksi Presiden Nomor 5 Tahun 2006 tentang Gerakan Nasional Percepatan Penuntasan Wajib Belajar Pendidikan Dasar
Sembilan Tahun Percepatan dan pemberantasan buta aksara

15. Peraturan Menteri Keuangan Nomor 134/PMK.06/2005 tentang PedomanPembayaran Dalam Pelaksanaan Anggaran dan Pendapatan Belanja Negara

16. Peraturan Menteri Pendidikan Nasional Republik Indonesia Nomor 28 tahun 2007tentang Organisasi dan Tata Kerja Balai Pengembangan Pendidikan Nonformaldan Informal

17. Peraturan Menteri Pendidikan Nasional Republik Indonesia Nomor 8 tahun 2008tentang Organisasi dan Tata Kerja Pusat Pengembangan Pendidikan Nonformaldan Informal

18. Peraturan Menteri Pendidikan Nasional Nomor 2 Tahun 2010 tentang RencanaStrategis Kementrian Pendidikan Nasional Tahun 20102014

19. Peraturan Menteri Pendidikan Nasional Nomor 36 tahun 2010 tentang Organisasidan Tata Kerja di lingkungan Kementerian Pendidikan Nasional

20. Peraturan Direktur Jenderal Perbendaharaan Nomor Per-66/PB/2005 tentang Mekanisme Pelaksanaan Pembayaran atas beban APBN

21. Peraturan Menteri Pendidikan Nasional Nomor 7 Tahun 2009, tentang Pedoman Pemberian Bantuan kepada Pendidikan Nonformal dan Informal

Seiring dengan perkembangan zaman tuntutan terhadap anak untuk melakukan berbagai macam aktivitas semakin meningkat. Tak terkecuali anak- anak juga megalami hal yang sama. Bukan hanya aktivitas yang meningkat persaingan hidup setelah mereka bernajak dewasa. Oleh karena itu, mereka perlu dibekali dengan berbagai macam problem solving untuk menghadapi tantangan masa depan. Salah satu problem solving oleh pengabdian masyarakat kali ini adalah tentang progam pedampinga dan penyelenggaraan pendidikan anak usia dini terhadap prestasi belajar . Terselenggaranya layanan prima 


\section{Loyalitas Kreativitas \\ Aldi Masyarakat Kreatif}

P-ISSN 2722-2101, E-ISSN 2722-4201

Program Studi Ekonomi Manajemen Universitas Pamulang Jurnal LOKABMAS Kreatif Vol. 01, No. 01, Hal. 71- 75

Email:jurnalkreatif.manajemen@gmail.com pendidikan untuk membentuk insan Indonesiacerdas dan komprehensif telah menjadi visi dari Kementerian Pendidikan danKebudayaan yang diwujudkan melalui berbagai.Melanjutkan program pembangunan $p$ endidikan yang menekankan pada peningkatan kapasitas dan modernisasi, kini Kementerian Pendidikan dan Kebudayaan memasuki tahun kedua pelaksanaan program pendidikan dalam kerangka tema strategis penguatan pelayanan pendidikan. Dalam kurun waktu 2014-2018, fokus sasaran dan program kerja pembangunan pendidikan harus mampu menjawab tuntutan mutu dari kapasitas pendidikan yang semakin besar dengantetap berupaya mendorong akses pendidikan yang semakin meluas, mudah, dan akun tabel.Memasuki tahun 2019, seiring catatan pencapaian pelaksanaan program tahun 2013 dan adanya kebijakan reformasi birokrasi (restrukturisasi) di lingkungan Kementerian Pendidikan dan Kebudayaan, Direktorat Jenderal Pendidiikan Anak Usia Dini, Nonformal dan Informal (PAUDNI)telah menyusun kebijakan dan programtahun 2019 sesuai dengan tuntunan beban garapan yang semakin besar dengan tetap memperhatikan keberlanjutan dan peningkatan kualitas pencapaian program dalam kerangka visi, misi, dan strategi pembangunan pendidikan nasional secara keseluruhan. sesuai dengan tujuan, target, dan sasaran sebagaimana telah digariskan dalam Daftar Isian Pelaksanaan Anggaran(DIPA) Ditjen PA UDNI tahun 2019. Oleh karena itu, Ditjen PAUDNI menerbitkan Pedoman Pelaksanaan Program PAUDNI tahun 2019 sebagai pedoman umum pelaksanaan program PAUDNI tahun 2019, yang akan diikuti oleh penerbitan pedoman-pedoman teknis pelaksanaan lainnya oleh masing-masing satuan kerja. Dengan pedoman ini diharapkan program PAUD

ini dapat dilaksanakan secara lebih seksama dengan baik dengan tetap memberikan ruang gerak yang positif bagi semua pemangku kepentingan untuk berinovasi dan berkreasi sesuai dengan kondisi yang berkembang di lapangan sepanjang tidak bertentangan dengan peraturan perundang-undangan yang berlaku

\section{HASIL DAN PEMBAHASAN}

Kegiatan Pengabdian Masyarakat Universitas Pamulang yang dilakukan oleh dosen-dosen program studi Manajemen telah berjalan dengan lancar dan mendapat sambutan hangat dari tempat pelaksanaan kegiatan ini yaitu di dilingkungan rt 20 rw 09 kel.giri peni, kel wates, yogyakarta

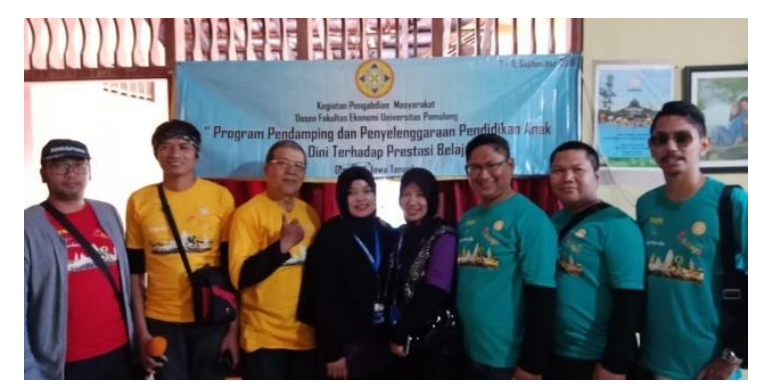

Harapan kami dengan pengabdian ini adalah meningkatnya pengetahuan penyuluhan materi progam pendampingan dan penyelengaraan pendidikan anak usia dini terhadap prestasi belajar

\section{KESIMPULAN DAN SARAN Kesimpulan}

Pengetahuan dan pemahaman orang tua dan anak- anak di lingkungan rt 20 rw 09 kel giri peni, kec.wates, Yogyakarta tentang penyuluhan materi progam pendampingan dan penyelengaraan pendidikan anak usia dini terhadap prestasi belajar

\section{Saran}

Mengadakan sosialisasi dan pelatihan serupa pada Lingkungan lain di Kecamatan yang lain, dengan materi yang serupa. Adanya kesinambungan program pasca kegiatan pengabdian ini sehingga para siswa benar-benar dapat mengembangkan kemampuannya dalam berkreasi. Diadakannya kegiatan yang berkaitan dengan pemasaran produk yang sudah dihasilkan.

\section{DAFTAR PUSTAKA}

Muljono, Ryan Kristo. 2018. Digital Marketing Concept. Gramedia Pustaka Utama. Jakarta. 


\section{Loyalitas Kreativitas \\ Aldi Masyarakat Kreatif}

P-ISSN 2722-2101, E-ISSN 2722-4201

Program Studi Ekonomi Manajemen Universitas Pamulang Jurnal LOKABMAS Kreatif Vol. 01, No. 01, Hal. 71- 75

Email:jurnalkreatif.manajemen@gmail.com

Pasaribu, V. L. D., Agrasadya, A., Shabrina, N., \& Krisnaldy, K. (2020). MENJADI ENTERPRENEUR MUDA YANG MEMILIKI JIWA LEADERSHIP UNTUK MENGHADAPI MASA DEPAN. Abdi Laksana, 1(1).

Pasaribu, V. L. D., Elburdah, R. P., Sudarso, E., \& Fauziah, G. (2020). PENGGUNAAN MANAJEMEN WAKTU TERHADAP PENINGKATAN PRESTASI BELAJAR DI SMP ARAISIYAH. Jurnal ABDIMAS, 1(1).

Paluzi, Hanna. 2016. Kreasi Perca (Buku Kreasi Anak). Indiva Media Kreasi. Surakarta.

Tripratiwi, Agni. 2015. Desain Flanel dan Perca. Tiara Aksa. Surabaya.

https://www.jurnal.id/id/blog/4-jenis-strategipemasaran-produk-yang-perlu-anda-ketahui/

https://databermanfaat.blogspot.com/2014/06/b erbagi-makalah-bertemakan-kain-perca.html

https://bisnisukm.com/memanfaatkan-kainperca-sebagai-peluang-usaha.html

https://olympics30.com/kerajinan-darikain-perca/

\section{DOKUMENTASI KEGIATAN}
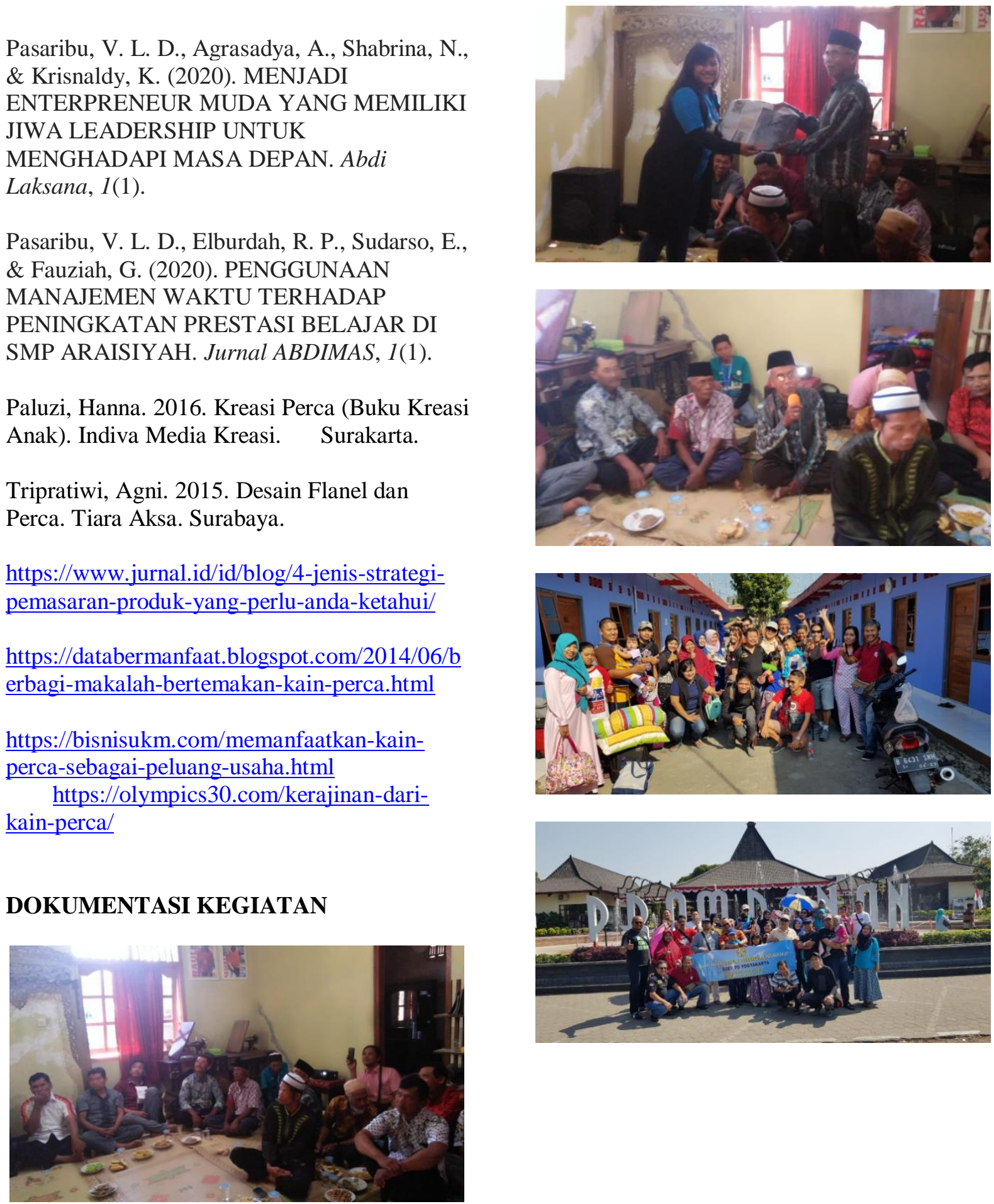